\title{
Unil
}

UNIL | Université de Lausanne

Unicentre

$\mathrm{CH}-1015$ Lausanne

http://serval.unil.ch

Year : 2015

\section{Surgery for unruptured arteriovenous malformations of the brain is better than conservative management for selected cases : a prospective cohort study}

\author{
BERVINI David
}

BERVINI David, 2015, Surgery for unruptured arteriovenous malformations of the brain is better than conservative management for selected cases : a prospective cohort study

Originally published at: Thesis, University of Lausanne

Posted at the University of Lausanne Open Archive http://serval.unil.ch

Document URN : urn: nbn:ch:serval-BIB_295A1A5EADC87

\section{Droits d'auteur}

L'Université de Lausanne attire expressément l'attention des utilisateurs sur le fait que tous les documents publiés dans l'Archive SERVAL sont protégés par le droit d'auteur, conformément à la loi fédérale sur le droit d'auteur et les droits voisins (LDA). A ce titre, il est indispensable d'obtenir le consentement préalable de l'auteur et/ou de l'éditeur avant toute utilisation d'une oeuvre ou d'une partie d'une oeuvre ne relevant pas d'une utilisation à des fins personnelles au sens de la LDA (art. 19, al. 1 lettre a). A défaut, tout contrevenant s'expose aux sanctions prévues par cette loi. Nous déclinons toute responsabilité en la matière.

\section{Copyright}

The University of Lausanne expressly draws the attention of users to the fact that all documents published in the SERVAL Archive are protected by copyright in accordance with federal law on copyright and similar rights (LDA). Accordingly it is indispensable to obtain prior consent from the author and/or publisher before any use of a work or part of a work for purposes other than personal use within the meaning of LDA (art. 19, para. 1 letter a). Failure to do so will expose offenders to the sanctions laid down by this law. We accept no liability in this respect. 
UNIVERSITE DE LAUSANNE - FACULTE DE BIOLOGIE ET DE MEDECINE

Département des Neurosciences Cliniques

Service de Neurochirurgie

Surgery for unruptured arteriovenous malformations of the brain is better than conservative management for selected cases: a prospective cohort study

\section{THESE}

préparée sous la direction du Professeur Roy T Daniel

et présentée à la Faculté de biologie et de médecine de

l'Université de Lausanne pour l'obtention du grade de

\section{DOCTEUR EN MEDECINE}

par

David BERVINI

Médecin diplômé de la Confédération Suisse

Originaire de Melano (Tessin)

Lausanne 


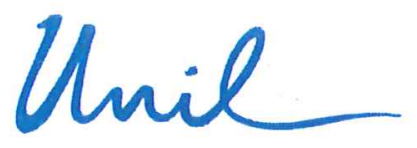

UNIL | Université de Lausanne

Faculté de biologie et de médecine

Ecole Doctorale

Doctorat en médecine

\section{Imprimatur}

Vu le rapport présenté par le jury d'examen, composé de

Directeur de thèse Monsieurle Professeur Prof. Roy Thomas Daniel

Co-Directeur de thèse

Expert

Directrice de l'Ecole Madame la Professeure Stephanie Clarke doctorale

la Commission MD de l'Ecole doctorale autorise l'impression de la thèse de

\section{Monsieur David BER VINI}

intitulée

Surgery for unruptured arteriovenous malformations of the brain is better than conservative management for selected patients: a prospective cohort study

Lausanne, le 17 février 2015

pour Le Doyen

de la Faculté de Biologie et de Médecine

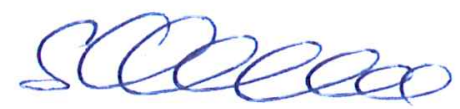

Madame la Professeure Stephanie Clarke Directrice de l'Ecole doctorale 
LE TRAITEMENT CHIRURGICAL DES MALFORMATIONS ARTÉRIOVEINEUSES CÉRÉBRALES NON ROMPUES EST SUPÉRIEUR AU TRAITEMENT CONSERVATEUR POUR DES CAS SÉLECTIONNÉS: UNE ÉTUDE DE COHORTE PROSPECTIVE

\title{
(SURGERY FOR UNRUPTURED ARTERIOVENOUS MALFORMATIONS OF THE BRAIN IS BETTER THAN CONSERVATIVE MANAGEMENT FOR SELECTED CASES: A PROSPECTIVE COHORT STUDY)
}

\author{
David Bervini, MADvSurg; Michael K Morgan, MD; Elizabeth A Ritson, MBBS and Gillian Heller, PhD
}

Introduction: Le risque hémorragique d'une malformation artérioveineuse cérébrale non rompue (MAVnr) est d'environ $2.2 \%$ par année ${ }^{1}$ et de $29 \%$ sur 20 ans. $^{2}$ Différents facteurs pouvant modifier ce risque entrent en ligne de compte. Les conséquences d'une première hémorragie liée à une malformation artérioveineuse peuvent être dévastantes, caractérisées par des taux combinés de morbidité/mortalité élevés (41\%-85\%).3-6 Les risques de la prise en charge chirurgicale sont quant à eux variables et peuvent être estimés en faisant recours à la classification de Spetzler-Martin ${ }^{7}$ et à sa réduction en trois tiers (Spetzler-Ponce Classes) ${ }^{8}$, celle-ci tenant compte de trois caractéristiques: taille, drainage veineux profond et localisation en territoire éloquant. Cependant, il n'existe pas à ce jour d'études validant la classification de Spetzler-Martin pour ce qui est des MAVnr, d'où l'importance de toute étude de cohorte basée sur de larges banques de données collectées de manière prospective. Pour ce faire, nous avons analysé notre banque de données en comparant l'histoire naturelle (risque hémorragique) avec le risque lié au traitement chirurgical des MAVnr, en incluant également les patients n'ayant pas bénéficié d'une prise en charge chirurgicale (analyse de sensibilité). Une des limitations de notre étude est celle de ne pas être randomizée. Ceci-dit, nous avons essayé de fournir suffisament d'informations pour comprendre comment cela pourrait influencer notre analyse, nos résultats et notre conclusion.

Le but de cette étude est celui d'identifier quels patients sont des candidats à pouvoir bénéficier d'un traitement chirurgical de leur MAVnr.

Méthodes: Notre banque de données a été interrogée quant au risques liés à l'hémorragie versus ceux liés au traitement chirurgical. Les résultats de la chirurgie ont été analysés en incorporant également les cas récusés parce que perçus comme à risque pour la chirurgie-même (analyse de sensibilité). Cela a permis de comparer les risques selon l'histoire naturelle avec ceux liés à la prise en charge chirurgicale. Nous avons analysé les données de 427 patients diagnostiqués avec une MAVnr (y compris les cas traités conservativement), enregistrés prospectivement et de manière consécutive dans notre banque de données. L'analyse de survie quant au risque hémorragique selon l'histoire naturelle a été calculée par la méthode de Kaplan-Meier. L'étude des facteurs de risque potentiels a été effectuée en utilisant les modèles de regression Cox et d'analyse de survie selon KaplanMeier, en se basant sur le laps de temps entre la première consultation et le premier des évènements suivants: hemorragie, traitement ou date de la dernière consultation. Les résultats de la chirurgie (et de sa morbidité avec un nouveau déficit avec modified Rankin Scale [mRS] >1) ont été établis. L'analyse de sensibilité a par la suite été effectuée en incluant les cas récusés du traitement chirurgical à cause leur risque et en considérant ceux-ci comme ayant présenté une complication chirurgicale.

Résultats: Au total, 377 patients avec un MAVnr ont pu être inclus dans l'analyse du risque hémorragique selon l'histoire naturelle. Ce risque est de $11.5 \%$ sur 5 ans. L'hémorragie a été responsable d'une dégradation neurologique avec mRS>1 chez 14 cas (88\% [95\% CI 63\%-98\%]). Pour les patients avec une MAVnr SpetzlerPonce Class A traités chirurgicalement $(\mathrm{n}=190)$, une dégradation neurologique permanente s'est présentée chez $1.6 \%$ (95\% CI $0.3 \%-4.8 \%$ ) des cas pour un mRS $>1$ et respectivement chez $0.5 \%(95 \% \mathrm{CI}<0.1 \%-3.2 \%)$ des cas pour un mRS $>2$. Pour les patients avec une MAVnr Spetzler-Ponce Class B traité chirurgicalement $(\mathrm{n}=107)$, une dégradation neurologique permanente avec un mRS $>1$ s'est présentée chez $14.0 \%$ des cas $(95 \%$ CI $8.6 \%-$ $22.0 \%$ ). L'analyse de sensibilité pour les MAVnr Spetzler-Ponce Class B, incluant les patients récusés du traitement chirurgical, a démontré que les risques de dégradation neurologique avec mRS $>1$ auraient pu atteindre les 15.6\% (95\% CI 9.9\%-23.7\%) si l'on avait considéré les patients récusés comme ayant présenté un mauvais résultat chirurgical et un $m R S>1$. Pour les patients avec une MAVnr Spetzler-Ponce Class $C$ traités chirurgicalement $(n=44)$ une dégradation neurologique permanente avec un mRS $>1$ s'est présentée chez 38.6\% des cas (95\% CI 25.7\%-53.4\%). L'analyse de sensibilité des MAVnr Spetzler-Ponce Class C, incluant les patients récusés du traitement chirurgical, a démontré que le risque réel de dégradation neurologique avec mRS $>1$ aurait pu atteindre les $60.9 \%$ (95\% CI 49.2\%-71.5\%) s'il l'on avait considéré les patients récusés comme ayant présenté un mauvais résultat chirurgical et un mRS $>1$.

Conclusions: Pour les malformations artérioveineuses non rompues Spetzler-Ponce Classe A le traitement chirurgical est supérieur au traitement conservateur. 


\section{Références:}

1. Gross BA, Du R: Natural history of cerebral arteriovenous malformations: a meta-analysis. Clinical article. J Neurosurg 118:437-443, 2013

2. Hernesniemi JA, Dashti R, Juvela S, Väärt K, Niemelä M, Laakso A: Natural history of brain arteriovenous malformations: a long-term follow-up study of risk of hemorrhage in 238 patients. Neurosurgery 63:823-831, 2008

3. Brown RD Jr, Wiebers DO, Forbes G, O'Fallon WM, Piepgras DG, Marsh WR, et al: The natural history of unruptured intracranial arteriovenous malformations. J Neurosurg 68:352- 357, 1988

4. Crawford PM, West CR, Chadwick DW, Shaw MD: Arterio- venous malformations of the brain: natural history in unoperated patients. J Neurol Neurosurg Psychiatry 49:1-10, 1986

5. da Costa L, Wallace MC, Ter Brugge KG, O'Kelly C, Wil- linsky RA, Tymianski M: The natural history and predictive features of hemorrhage from brain arteriovenous malformations. Stroke 40:100-105, 2009

6. Ondra SL, Troupp H, George ED, Schwab K: The natural history of symptomatic arteriovenous malformations of the brain: a 24-year follow-up assessment. J Neurosurg 73:387- 391, 1990

7. Spetzler RF, Martin NA: A proposed grading system for arteriovenous malformations. J Neurosurg 65:476-483, 1986

8. Spetzler RF, Ponce FA: A3-tier classification of cerebral arteriovenous malformations. Clinical article. J Neurosurg 114: 842-849, 2011 


\title{
Surgery for unruptured arteriovenous malformations of the brain is better than conservative management for selected cases: a prospective cohort study
}

\author{
Clinical article
}

\author{
David Bervini, M.Adv.Surg., ${ }^{1}$ Michael Kerin Morgan, M.D., ${ }^{1}$ \\ Elizabeth Anne Ritson, M.B.B.S., ${ }^{2}$ and Gillian Heller, Ph.D. ${ }^{3}$ \\ ${ }^{1}$ Australian School of Advanced Medicine, ${ }^{2}$ Macquarie University Hospital, and ${ }^{3}$ Statistics Department, \\ Macquarie University, Sydney, New South Wales, Australia
}

Object. The aim of this study was to identify patients who are likely to benefit from surgery for unruptured brain arteriovenous malformations (ubAVMs).

Methods. The authors' database was interrogated for the risk and outcome of hemorrhage after referral and the outcome from surgery. Furthermore, the outcome from surgery incorporated those cases excluded from surgery because of perceived greater risk (sensitivity analysis). Finally, a comparison was made for the authors' patients between the natural history and surgery. Data were collected for 427 consecutively enrolled patients with ubAVMs in a database that included patients who were conservatively managed. Kaplan-Meier analysis was performed on patients observed for more than 1 day to determine the risk of hemorrhage. Variables that may influence the risk of first hemorrhage were assessed using Cox proportional hazard regression models and Kaplan-Meier life table analyses from referral until the first occurrence of the following: hemorrhage, treatment, or last review. The outcome from surgery (leading to a new permanent neurological deficit with last review modified Rankin Scale [mRS] score $>1$ ) was determined. Further sensitivity analysis was made to predict risk from surgery for the total ubAVM cohort by incorporating outcomes of surgical cases as well as cases excluded from surgery because of perceived risk, and assuming an adverse outcome for these excluded cases.

Results. A total of 377 patients with a ubAVM were included in the analysis of the risk of hemorrhage. The 5 -year risk of hemorrhage for ubAVM was $11.5 \%$. Hemorrhage resulted in an mRS score $>1$ in 14 cases $(88 \%$ [95\% CI 63\%-98\%]). Patients with Spetzler-Ponce Class A ubAVMs treated by surgery $(\mathrm{n}=190)$ had a risk from surgery of $1.6 \%(95 \%$ CI $0.3 \%-4.8 \%$ ) for a permanent neurological deficit leading to an mRS score $>1$ and $0.5 \%$ (95\% CI $<0.1 \%-3.2 \%$ ) for a permanent neurological deficit leading to an $\mathrm{mRS}$ score $>2$. Patients with Spetzler-Ponce Class B ubAVMs treated by surgery $(n=107)$ had a risk from surgery of $14.0 \%(95 \%$ CI $8.6 \%-22.0 \%)$ for a permanent neurological deficit leading to an mRS score $>1$. Sensitivity analysis of Spetzler-Ponce Class B ubAVMs, including those in patients excluded from surgery, showed that the true risk for surgically eligible patients may have been as high as $15.6 \%$ (95\% CI 9.9\%-23.7\%) for mRS score $>1$, had all patients who were perceived to have a greater risk experienced an adverse outcome. Patients with Spetzler-Ponce Class C ubAVMs treated by surgery $(\mathrm{n}=44)$ had a risk from surgery of $38.6 \%$ (95\% CI $25.7 \%-53.4 \%$ ) for a permanent neurological deficit leading to an mRS score $>$ 1. Sensitivity analysis of Class $\mathrm{C}$ ubAVMs, including those harbored by patients excluded from surgery, showed that the true risk for surgically eligible patients may have been as high as $60.9 \%$ (95\% CI $49.2 \%-71.5 \%$ ) for mRS score $>1$, had all patients who were perceived to have a greater risk experienced an adverse outcome.

Conclusions. Surgical outcomes for Spetzler-Ponce Class A ubAVMs are better than those for conservative management.

(http://thejns.org/doi/abs/10.3171/2014.7.JNS132691)

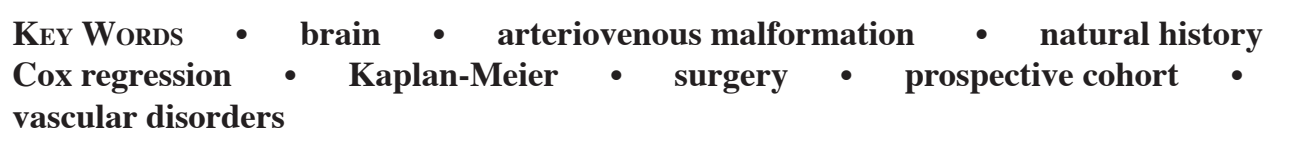

$\mathrm{T}$ HE risk of hemorrhage from unruptured brain arteriovenous malformations (ubAVMs) is approximately $2.2 \%$ per year. ${ }^{9}$ Even though a number of risk factors have been proposed that may modify this overall rate, ${ }^{2-4,8,10-12,21,22,27-30,33}$ an analysis of the literature shows

Abbreviations used in this paper: ARUBA = A Randomized Trial of Unruptured Brain Arteriovenous Malformations; AVM = arteriovenous malformation; bAVM = brain AVM; DSA = digital subtraction angiography; $\mathrm{mRS}=$ modified Rankin Scale; RCT = randomized controlled trial; ubAVM = unruptured brain AVM. that recent diagnosis, deep location, and associated aneurysms may be associated with an increased risk of future hemorrhage. ${ }^{9}$ Presentation with hemorrhage is also a reported risk factor ${ }^{3,4,7,7,10-12,21,28,31,33}$ but does not relate to our study looking at only ubAVMs. The cumulative risk of first hemorrhage over 20 years has been reported to be $29 \% .^{11}$

The consequence of a hemorrhage occurring in a diagnosed ubAVM while under surveillance is significant. Mortality of $6 \%-29 \%$, permanent morbidity of $16 \%-$ $35 \%$, and combined morbidity and mortality of $41 \%-85 \%$ have been reported..$^{2-4,20}$ 
The risk from surgery for brain AVMs has been stratified by the Spetzler-Martin grading system using 3 components of the AVM: size, deep venous drainage, and eloquent location. ${ }^{5,13,23,25,26}$ The importance of this grading system is to assist in selection of cases with a low risk of permanent adverse outcomes from surgery. It has been recommended by Spetzler and Ponce that the grading system can best be reduced to 3 tiers: Spetzler-Martin Grades I and II (Spetzler-Ponce Class A), Spetzler-Martin Grade III (SpetzlerPonce Class B), and Spetzler-Martin Grades IV and V (Spetzler-Ponce Class C). ${ }^{26}$ This risk has been reported to be $8 \%$ in a combined series for Spetzler-Ponce Class A ubAVMs and no greater than $1 \%$ in 3 series. ${ }^{26}$ Some series reported the lack of impact of size or eloquent location of AVMs on surgical outcome. ${ }^{14,24}$ This may be explained by cohort surgical series that do not take into consideration patients at high risk because they have been excluded from surgical treatment. Davidson and Morgan attempted to account for the patients who had been excluded from surgical treatment and concluded that all the variables of the Spetzler-Martin grading system were of importance and that the Spetzler-Martin grading system was a reliable way of stratifying risks from surgery. ${ }^{5}$ The principle for this 3-tier grading is based upon series incorporating both ruptured and unruptured brain AVMs (bAVMs). The application of the Spetzler-Martin grading system for risk from surgery is likely reasonable. However, no large series of ubAVMs report on the application of the Spetzler-Martin grading system in predicting surgical outcome to date. We showed that the risks reported for outcome for surgery for Spetzler-Ponce Class A ubAVMs could be generalized to all patients suitable for surgery with Spetzler-Ponce Class A ubAVMs (both operated and unoperated) due to the very high proportion of patients treated by surgery, whereas the surgical series results for Spetzler-Ponce Class B and Spetzler-Ponce Class C ubAVMs could not be generalized due to selection bias (that is, exclusion of high-risk cases in surgical series). This bias relates to patients excluded from surgery because of perceived surgical risk. ${ }^{5}$ If this number is a large percentage of the group as a whole, the surgical risk reported will underestimate the risks for all patients with similar Spetzler-Ponce class ubAVMs.

Because of the complexity of potential risks of first hemorrhage, the variability in outcomes of management, and the perceived absence of compelling data from case series, A Randomized Trial of Unruptured Brain Arteriovenous Malformations (ARUBA) was undertaken. Within ARUBA, $7.9 \%$ (10 patients) of the medical management arm experienced death or stroke compared with 35\% (34 patients) of the interventional therapy arm over 33 months with a relative risk of 0.35 (95\% CI $0.19-0.65) .{ }^{1}$ This study was performed to "compare the risk of death and symptomatic stroke in patients with an unruptured brain arteriovenous malformation who are allocated to either medical management alone or medical management with planned efforts at eradication of the brain arteriovenous malformation with interventional therapy." 17 This interventional therapy included some surgery for $16 \%$ (the sole modality in $4 \%$ of cases), radiotherapy (presumably focused irradiation) in $26 \%$, and some contribution by embolization in $40 \%$ (the sole modality in $26 \%$ of cases). ${ }^{17}$
Although ARUBA was initially aimed and powered to recruit 800 patients, the study was ultimately analyzed for a total of 223 patients from 39 centers. The difficulty of recruitment encountered with ARUBA is unlikely to be overcome with future randomized controlled trials (RCTs) due to the need for "ethical equipoise" and the increasing knowledge of the natural history of ubAVMs, the low surgical risks for Spetzler-Ponce Class A ubAVMs, and the high surgical risks for Spetzler-Ponce Class C ubAVMs. Therefore, a role remains for large cohort series from prospectively collected databases (with enough information for the selection bias available to the reader) to provide evidence to answer the question, "Can treatment be superior to nontreatment for ubAVM?"

We performed an analysis of a prospectively collected database of ubAVMs for both the natural history of hemorrhage and the risk from surgery. The database included patients who underwent surgery and those who were conservatively managed. We performed a sensitivity analysis to include how the patients who did not undergo surgery might have influenced the predicted outcome from surgery for all cases of similar Spetzler-Ponce class ubAVMs had they undergone surgery and had an adverse outcome from surgery. The initial recommendation of the surgeon and the decision made by the patient were recorded. The risk from surgery for those patients recommended for surgery but who were treated elsewhere or refused recommended management is unlikely to have changed the risk occurring in our analyzed series of patients undergoing surgery. However, for those patients recommended by the surgeon for conservative treatment because of the perceived risk from surgery, predicted outcomes (if surgery had been performed) could be expected to be worse than for those with similar Spetzler-Ponce class ubAVMs undergoing surgery. Although age and some comorbidity are not necessarily a barrier for surgical treatment, for the purpose of the sensitivity analysis in this report, we considered patients younger than 65 years and without significant comorbidity as eligible for surgery. These eligible patients were incorporated into the sensitivity analysis to improve the external validity (generalizability) of the reported risk from surgery.

A limitation of our study is that this is a prospective cohort study and patients were not randomly chosen for surgery versus conservative management. However, we have attempted to provide sufficient information to understand how this may have impacted outcome, analysis, and conclusions.

\section{Methods}

\section{Patient Population}

This study was approved by the Macquarie University Human Ethics Committee and was performed in accordance with institutional ethics committee guidelines. A prospectively collected database of the senior author (M.K.M.) of consecutive patients who harbored bAVMs was retrospectively analyzed for the years 1989 to September 2013. The responsibility for entry into the database was that of the senior author. However, the database 
was accessible to residents, fellows, and occupational therapists at the time of assessment and follow-up. The database contained demographic, clinical, radiological, and treatment-related information. Patients were included if they were confirmed to have a ubAVM on MRI, CT angiography, or digital subtraction angiography (DSA), and if they had at least 1 follow-up review after the initial referral. The Spetzler-Ponce class was allocated when sufficient radiological detail had been obtained to grade the ubAVM and was allocated prior to surgery. Hemorrhage, in those followed to establish the natural history, was considered a new neurological deficit if there was a radiological confirmation of hemorrhage and it could be related to the ubAVM. The adverse events from surgery were considered to be new permanent neurological deficits (assigned within the first 6 weeks of surgery) with a modified Rankin Scale (mRS) score $>1$ (assigned at last follow-up consultation) due to preoperative embolization or surgery. The mRS score assigned to each patient was subject to open access to fellows, occupational therapists, and other neurosurgeons on follow-up consultations.

\section{Risk of Hemorrhage for Untreated ubAVMs}

For the study of the risk of hemorrhage, all patients with a ubAVM irrespective of management plan were analyzed. Patients were excluded if they had only 1 contact date, if they were treated on the same day of referral, if they did not have a parenchymal bAVM, if they had a history of hemorrhage from the bAVM, or if they presented with hemorrhage from the bAVM. For the Kaplan-Meier analysis of the risk of hemorrhage for this study group, the initial date was taken as the first of either the available date of referral or first consultation. The event was hemorrhage caused by the bAVM (confirmed by CT scan or MRI). In the absence of an event, the cases were censored at the first of either the first date of treatment (by embolization, focused irradiation, or surgery) or last follow-up. Analyzed ubAVM characteristics were 1) presentation with and without seizure; 2) presentation with and without neurological deficits (unrelated to seizure or hemorrhage); 3) presence or absence of aneurysm (intranidal or located on feeding arteries) on initial DSA; 4) age (as a continuous variable); 5) supratentorial versus infratentorial location; 6) deep (either brainstem or bAVM with no pial surface) versus superficial location; 7) presence or absence of exclusive deep venous drainage; 8) maximum size (as a continuous variable); and 9) sex.

\section{Risk From Surgery for ubAVMs}

The outcomes from surgery leading to a new neurological deficit with last review mRS score $>1$ (as well as mRS score $>2$ ) was determined for ubAVMs using the Spetzler-Ponce grading system. Analysis was first made for patients undergoing surgery. In addition, a sensitivity analysis was performed incorporating patients undergoing surgery with the addition of eligible patients $(<65$ years and without significant comorbidity) who were not surgically treated because of perceived risk from surgery (as recorded at the time of the initial management decision). These added patients who did not undergo surgery were assumed to have an adverse outcome for the purpose of the sensitivity analysis. The surgery group included patients who had preoperative embolization. Adverse outcomes attributed to embolization were included as surgical adverse events.

\section{Statistical Analysis}

Statistical analysis was performed using Prism software (version 6, GraphPad Software Inc.) and IBM SPSS Statistics (version 21, IBM Corp.). For the risk of hemorrhage from untreated ubAVMs, univariate Cox regression was performed for each variable to calculate the hazard ratios and 95\% confidence intervals. For the risk from surgery analysis, comparison by Spetzler-Ponce groups was performed using the Pearson chi-square test for categorical variables and ANOVA for continuous variables. A statistical significance level of $p<0.05$ was used throughout.

\section{Results}

From 760 consecutive patients with bAVMs, 427 patients with ubAVMs were identified. The other 333 patients had a history of hemorrhage. The flowchart of analysis is provided in Fig. 1.

\section{Risk of Hemorrhage for ubAVMs}

Of the 427 patients with a ubAVM, 377 were analyzed for the risk of hemorrhage. Fifty patients were excluded as they were either treated on the day of referral or were reviewed on only 1 occasion. The mean time interval between initial referral and censoring (that is, the first of either the 1st day of treatment or last day of follow-up) or event (hemorrhage) was 270 days (range 1-5840 days), for a total of 279 case-years of follow-up.

Hemorrhage after referral, unrelated to treatment, occurred in 16 patients (Table 1). The overall outcomes from hemorrhage were a permanent downgrade in function to an mRS score $>1$ in $88 \%$ (95\% CI 63\%-98\%; 14 of 16 patients) and an mRS score > 2 in $69 \%(95 \%$ CI $44 \%-86 \% ; 11$ of 16 patients), including death in $31 \%$ (95\% CI $14 \%-56 \%$; 5 of 16 patients). The baseline characteristics for the patients with a ubAVM and the variables examined are reported in Table 2. For the entire group, the number of patients at risk had declined to 20 by 5 years. The cumulative rate of ubAVM hemorrhage was $8.1 \%$ at 1 year using the Kaplan-Meier product-limit method and $5.7 \%$ if calculated as the number of patients with new hemorrhage during follow-up divided by caseyears of follow-up. At 5 years, the cumulative rate of ubAVM hemorrhage was $11.5 \%$ using the Kaplan-Meier product-limit method. This gives an annualized risk of first hemorrhage of $2.3 \%$ over the first 5 years. The cumulative risk of hemorrhage for different times and the number of cases at risk from the study cohort can be seen in Table 3 along with a literature review. The risk for the first 17 years from referral can be seen in Fig. 2 .

Influence of Variables in Predicting Hemorrhage of ubAVMs

Of the 9 variables examined by univariate Cox regression, deeply located (brainstem or not presenting on 


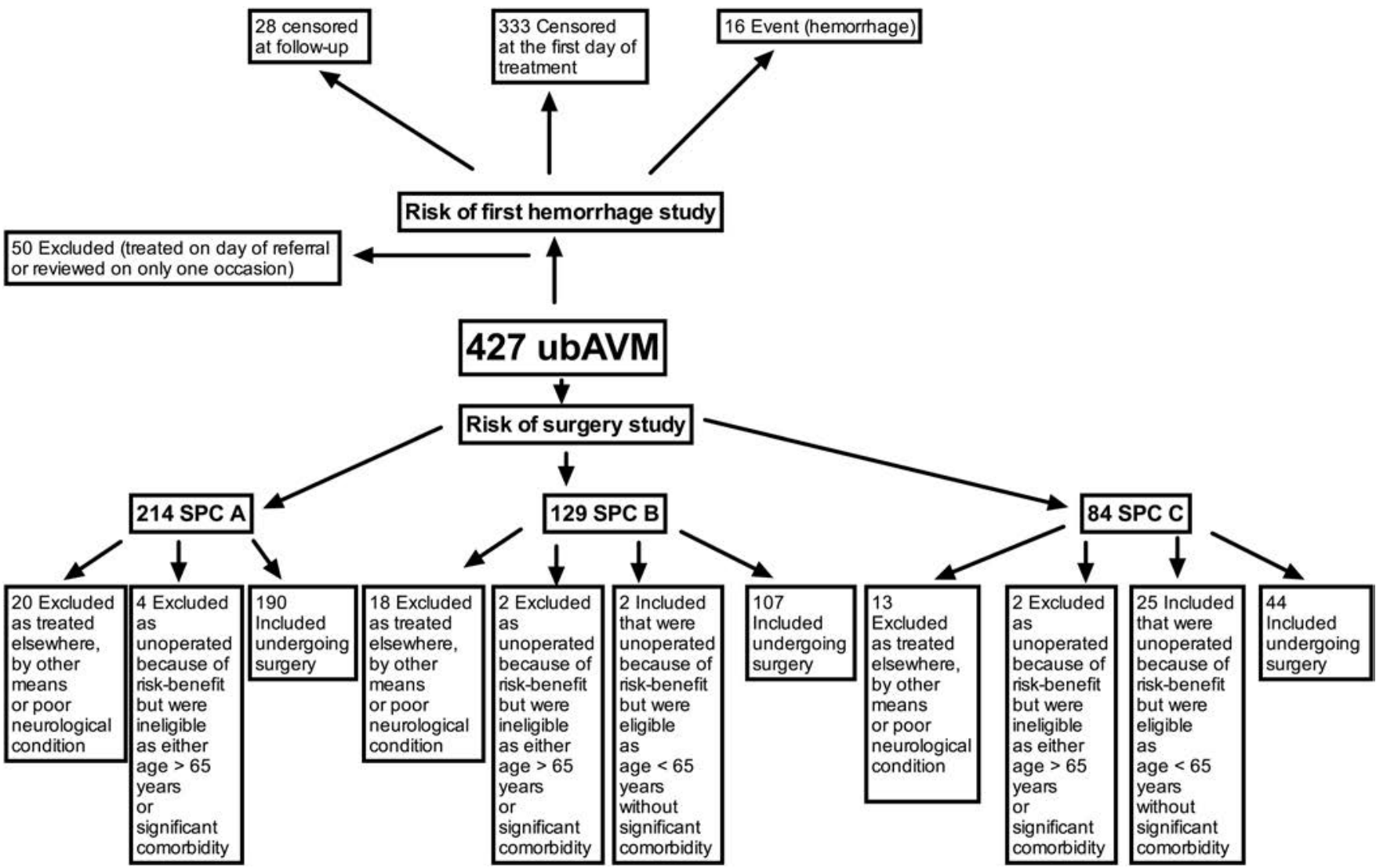

FIG. 1. Flowchart analysis. SPC $=$ Spetzler-Ponce Class.

any pial surface) ubAVMs had a significantly shorter time to hemorrhage ( $\mathrm{p}=0.032$, HR 3.78 [95\% CI 1.12-12.72]) (Table 2). However, the significance of this result needs to be treated with caution due to the number of variables examined (9) and the low number of events (4) occurring in the deep ubAVM group. Aneurysms were known to be present in $32 \%$ (119 of 377) of cases. This was not significant in predicting subsequent hemorrhage $(p=0.98)$. None of the 3 variables contributing to the Spetzler-Ponce class was significant in predicting the time to hemorrhage.

\section{Sensitivity Analysis of the Risk From Surgery (With or} Without Preoperative Embolization)

Of the 427 patients with a ubAVM, 368 were included in this analysis. Fifty-nine patients were excluded because they were treated by embolization only or were treated elsewhere (including those treated by focused irradiation). There was no case in which surgery was planned but not performed due to subsequent major adverse events from diagnostic DSA or embolization. Of these 368 patients, 27 eligible patients ( $<65$ years and no significant comorbidity) did not undergo surgery because of perceived risk of operative complications. There were no eligible patients excluded from surgery for a Spetzler-Ponce Class A ubAVM. For Spetzler-Ponce Class B ubAVMs, 2 eligible patients did not undergo surgery because of perceived risk of operative complications. For Spetzler-Ponce Class C ubAVMs, 25 eligible patients did not undergo surgery because of perceived risk of operative complications. The comparison between the results from surgery and that for the sensitivity analysis is shown in Fig. 3.

For patients with Spetzler-Ponce Class A ubAVMs treated by surgery, $1.6 \%$ (95\% CI $0.3 \%-4.8 \%$; 3 of 190 patients) experienced a new permanent neurological deficit from surgery with an mRS score $>1$ at last followup. For Spetzler-Ponce Class A ubAVMs, new permanent neurological deficits with an $\mathrm{mRS}$ score $>2$ at last followup were caused by surgery in $0.5 \%$ (1 of 190 [95\% CI < $0.1 \%-3.2 \%])$. Five patients with Spetzler-Ponce Class A ubAVMs were recommended for conservative management. These patients were either elderly (4 patients, 69-78 years) or had a significant comorbidity (1 patient with terminal liver failure). There were no eligible patients excluded from surgery because of perceived risk for Spetzler-Ponce Class A ubAVMs. The breakdown of the characteristics of cases as analyzed is presented in Table 4. The median time between referral and surgery for Spetzler-Ponce Class A ubAVMs was 27 days (25th percentile and 75th percentile of 10 and 60 days, respectively).

For patients with Spetzler-Ponce Class B ubAVMs treated by surgery, $14.0 \%$ (95\% CI 8.6\%-22.0\%; 15 of 107 patients) experienced a new permanent neurological deficit with an mRS score $>1$ at last follow-up from either embolization ( 2 cases) or surgery (14 cases; $13.1 \%$ [95\% CI $7.8 \%-20.9 \%$ ], including 1 patient who experienced 2 adverse events related to both preoperative embolization and surgery). For Spetzler-Ponce Class B ubAVMs treated by surgery, $2.8 \%$ (95\% CI $0.6 \%-8.3 \%$; 3 of 107 
TABLE 1: Patients experiencing their first bAVM hemorrhage after referral*

\begin{tabular}{|c|c|c|c|c|c|c|}
\hline $\begin{array}{l}\text { Case } \\
\text { No. }\end{array}$ & $\begin{array}{l}\text { Age (yrs), } \\
\text { Sex }\end{array}$ & $\begin{array}{l}\text { Spetzler-Martin Grade, } \\
\text { Side \& Location }\end{array}$ & Neurological Presentation & $\begin{array}{l}\text { Days Btwn Referral } \\
\& 1 \text { st Hemorrhage }\end{array}$ & $\begin{array}{l}\text { Outcome } \\
\text { mRS Score }\end{array}$ & $\begin{array}{c}\text { Complication Due to } \\
\text { Surgery Leading to } \\
\text { mRS Score }>1\end{array}$ \\
\hline 2 & $13, \mathrm{M}$ & II, It cerebellum & normal, seizure & 8 & 2 & none \\
\hline 3 & $45, M$ & III, It fronto-parietal & normal, seizure & 14 & 6 & NA \\
\hline 4 & $53, \mathrm{M}$ & IV, It basal ganglia & normal & 56 & 3 & none \\
\hline 6 & $17, \mathrm{M}$ & II, rt temporal & normal, seizure & 194 & 3 & none \\
\hline 7 & $42, F$ & III, rt frontal & normal, seizure & 218 & 6 & NA \\
\hline 8 & $36, F$ & III, rt frontal & normal & 330 & 6 & NA \\
\hline 9 & $43, \mathrm{~F}$ & IV, It parietal & mild hemiparesis \& dysphasia & 1057 & 3 & none \\
\hline 10 & $13, F$ & IV, It thalamic & normal & 2195 & 2 & NA \\
\hline 14 & $54, \mathrm{M}$ & III, It parietal & normal & 3065 & 3 & NA \\
\hline 15 & $44, \mathrm{M}$ & III, rt frontal & normal & 3086 & 3 & NA \\
\hline 16 & $44, \mathrm{M}$ & II, It cerebellum & normal & 3263 & 6 & NA \\
\hline
\end{tabular}

* NA = not applicable because surgery was not performed.

patients) experienced a new permanent neurological deficits with an $\mathrm{mRS}>2$ at last follow-up from either embolization ( 1 case) or surgery ( 3 cases; $2.8 \%$ [95\% CI $0.6 \%-8.3 \%$ ], including 1 patient who experienced 2 adverse events related to both preoperative embolization and surgery). Twenty-two patients with Spetzler-Ponce Class B ubAVMs were recommended for conservative management or were treated elsewhere. Of these, 2 (1.8\% of 109 combined patients at increased risk and patients undergoing surgery) who were eligible for surgery were excluded because of perceived increased risk from surgery. The breakdown of the characteristics of patients as analyzed is presented in Table 4. Had patients who were excluded because of perceived risk from surgery undergone surgery and experienced an adverse outcome, the risk of a new permanent neurological deficit with an $\mathrm{mRS}$ score $>1$ would have been $15.6 \%$ (95\% CI 9.9\%-23.7\%; 17 of 109 patients) and for an mRS score $>2$ it would have been $4.6 \%$ (95\% CI 1.7-10.6\%; 5 of 109 patients). The median time between referral and surgery for SpetzlerPonce Class B was 38 days (25th percentile and 75 th percentile of 9 and 94 days, respectively).

For patients with Spetzler-Ponce Class C ubAVMs treated by surgery, $38.6 \%$ (17 of 44 [95\% CI 25.7-53.4\%]) experienced a new permanent neurological deficit with an mRS score $>1$ at last follow-up from either embolization (2 patients) or surgery (15 patients; $34.1 \%$ [95\% CI $21.8 \%-48.9 \%])$.

For patients with Spetzler-Ponce Class C ubAVMs treated by surgery, $15.9 \%$ (7 of 44 [95\% CI 7.6\%-29.7\%]) experienced new permanent neurological deficits with an mRS score $>2$ at last follow-up from either embolization (2 patients) or surgery (5 patients; $11.4 \%$ [95\% CI $4.5 \%-24.4 \%])$. Forty patients with Spetzler-Ponce Class
C ubAVMs were recommended for conservative management or were treated elsewhere. Of these, 25 patients who were eligible for surgery (36.2\% of 69 combined patients with increased risk and patients undergoing surgery) were excluded because of perceived increased risk from surgery. The breakdown of the characteristics of cases as analyzed is presented in Table 4. Had patients excluded because of perceived risk from surgery undergone surgery and experienced an adverse outcome, the risk of a new permanent neurological deficit with an $\mathrm{mRS}$ score $>$ 1 would have been $60.9 \%$ (95\% CI $49.2 \%-71.5 \%$; 42 of 69 patients) and for mRS score $>2$ would have been $46.4 \%$ (95\% CI $36.5 \%-59.4 \%$; 32 of 69 patients). The median time between referral and surgery for Spetzler-Ponce Class C was 67 days (25th percentile and 75 th percentile of 36 and 176 days, respectively).

Complete bAVM resection was confirmed by postoperative DSA in 333 of 341 patients $(97.7 \%$ [95\% CI 95.4\%-98.9\%]). Three patients who had a persisting bAVM underwent further treatment to achieve DSAconfirmed complete resection by focused irradiation in 2 patients and endovascular treatment in 1 patient. Five patients died and did not undergo postoperative DSA. All patients with Spetzler-Ponce Class A ubAVMs (except for the patient who died of myocardial infarction during surgery) had confirmed complete resection of the bAVM by postoperative DSA.

\section{Risk of Hemorrhage for Untreated ubAVMs Compared With the Sensitivity Analysis of the Risk From Surgery}

Superimposing upon the Kaplan-Meier curve (of the risk of hemorrhage) the risk from surgery, the crossover occurred within 5 months for Spetzler-Ponce Class A 
TABLE 2: Characteristics of 377 patients with ubAVMs with a recorded referral date and subsequent date of hemorrhage or censoring (the earliest of last clinical review or treatment)*

\begin{tabular}{|c|c|c|c|c|}
\hline Variable & $\begin{array}{l}\text { No. of Patients w/ } \\
\text { Variable (\%) }\end{array}$ & $\begin{array}{c}\% \text { of Group Developing Hemorrhage } \\
\text { After Referral (actual no.) }\end{array}$ & $\mathrm{p}$ Value ${ }^{\dagger}$ & HR $(95 \%$ Cl) $\ddagger$ \\
\hline sex & & & & $0.83(0.31-2.25)$ \\
\hline $\mathrm{F}$ & $179(47.5)$ & $3.9(7$ of 179$)$ & & \\
\hline age in yrs (mean $37.4 \pm 15.6$ yrs) & & & 0.264 (continuous variable) & $1.02(0.99-1.05)$ \\
\hline $40-59$ & $120(31.8)$ & 6.7 (8 of 120$)$ & & \\
\hline $60-79$ & $35(9.3)$ & 5.7 (2 of 35$)$ & & \\
\hline$>79$ & $1(0.3)$ & $0(0$ of 1$)$ & & \\
\hline location & & & 0.159 & $2.50(0.70-8.94)$ \\
\hline infratentorial & $23(6.1)$ & 13 (3 of 23$)$ & & \\
\hline superficial & $345(91.5)$ & 3.5 (12 of 345$)$ & & \\
\hline maximum size & & & 0.282 (continuous variable) & $0.85(0.63-1.14)$ \\
\hline$<3 \mathrm{~cm}$ & $126(33.4)$ & $1.6(2$ of 126$)$ & & \\
\hline $3-6 \mathrm{~cm}$ & $217(57.6)$ & 6.0 (13 of 217$)$ & & \\
\hline$>6 \mathrm{~cm}$ & $34(9.0)$ & 2.9 (1 of 34$)$ & & \\
\hline deep venous drainage (exclusive) & & & 0.455 & $1.62(0.46-5.72)$ \\
\hline yes & $42(11.1)$ & 7.1 (3 of 42$)$ & & \\
\hline no & 335 (88.9) & $3.9(13$ of 335$)$ & & \\
\hline presentation w/ seizures & & & 0.479 & $0.70(0.26-1.89)$ \\
\hline seizures & $196(52.0)$ & $3.6(7$ of 196$)$ & & \\
\hline absent & $258(68.4)$ & 4.3 (11 of 258$)$ & & \\
\hline
\end{tabular}

* NA = not applicable.

$\dagger$ Univariate Cox regression.

‡ Univariate analysis.

$\S$ Deep = brainstem or not located on a pial surface.

ubAVMs, between 8 and 9 years for Spetzler-Ponce Class B ubAVMs, and did not occur for Spetzler-Ponce Class C ubAVMs for outcomes with mRS score $>1$ (Fig. 4). However, little reliance should be placed on the point of crossover if this is predicted to occur beyond 5 years because of the small number of patients remaining at risk at this time.

Superimposing upon the Kaplan-Meier curve (of the risk of hemorrhage) the risk from surgery, the crossover occurred before 5 months for Spetzler-Ponce Class A ubAVMs, between 6 and 8 months for Spetzler-Ponce Class B ubAVMs, and beyond 8 years for Spetzler-Ponce Class C ubAVMs for outcomes with mRS score > 2 (Fig. 4).
We further examined the relationship between the 95\% confidence intervals for both the natural history and sensitivity analysis of surgery (Fig. 4). That is, for this analysis, we included both those patients who underwent surgery as well as those who were excluded from surgery because of risk although eligible $(<65$ years and with no comorbidity). We wanted to know whether the upper $95 \%$ risk from surgery (that is, the lower 95\% confidence interval of being free of adverse outcomes) crossed the lowest 95\% risk of a hemorrhage causing a deficit (that is, the upper $95 \%$ confidence interval of being free of adverse outcomes). This was specifically performed for outcomes with $\mathrm{mRS}$ score $>1$ and $\mathrm{mRS}$ score $>2$. The upper $95 \%$ 
D. Bervini et al.

TABLE 3: Risk of hemorrhage reported in the literature (case series reporting more than 25 ubAVM cases) as well as present series*

\begin{tabular}{|c|c|c|c|c|c|c|}
\hline Authors \& Year & $\begin{array}{l}\text { Initial No. of } \\
\text { ubAVM } \\
\text { Cases at Risk }\end{array}$ & $\begin{array}{l}\text { \% 12-Mo Risk of } \\
\text { 1st Hemorrhage }\end{array}$ & $\begin{array}{l}\% \text { 5-Yr Risk of } \\
\text { 1st Hemorrhage }\end{array}$ & $\begin{array}{c}\text { \% Averaged Annualized } \\
\text { Risk of 1st Hemorrhage } \\
\text { From ubAVM }\end{array}$ & $\begin{array}{l}\text { Yrs of Follow-Up to } \\
\text { Which the Annual } \\
\text { Risk Applies }\end{array}$ & $\begin{array}{l}\text { Method of } \\
\text { Calculation }\end{array}$ \\
\hline Brown et al., 1988 & 168 & 1.3 & 8.5 & 2.3 & 15 & Kaplan-Meier \\
\hline Pollock et al., 1996 & 119 & $1.9 \dagger$ & $9.5 \dagger$ & 1.9 & NA & patient-yr method \\
\hline Halim et al., 2004 & 423 & 3 & 9 & 2 & 10 & Kaplan-Meier \\
\hline Yamada et al., 2007 & 146 & $3.1 \dagger$ & $15.5 \dagger$ & 3.1 & 5 & patient-yr method \\
\hline Kim et al., 2007 & $781 \S$ & $1.4 \dagger$ & $7 \dagger$ & 1.4 & 5 & Kaplan-Meier \\
\hline da Costa et al., 2009 & 420 & $3.6 \pi$ & $18 \ddagger$ & 3.6 & 5 & patient-yr method \\
\hline Hernesniemi et al., 2008 & 99 & $2.3 \dagger$ & 10 & 2.3 & 5 & patient-yr method \\
\hline ARUBA, $2013^{17}$ & 125 & 2.2 & $12 \ddagger$ & 2.3 & 5 & Kaplan-Meier \\
\hline
\end{tabular}

confidence interval for the natural history (of hemorrhage leading to a permanent neurological deficit) and the lower 95\% confidence interval of surgery (being free of adverse outcomes leading to a permanent neurological deficit) were superimposed to identify when the upper $90 \%$ confidence (combining the two 95\% confidence intervals) of surgery risk crossed the natural history risk. The mRS score $>1$ upper $95 \%$ confidence interval was crossed by the lower outcome Spetzler-Ponce Class A at 3065 days. Such crossing did not occur for either Spetzler-Ponce Class B or Spetzler-Ponce Class C ubAVMs. The mRS score $>2$ upper $95 \%$ confidence interval was crossed by the lower outcome Spetzler-Ponce Class A ubAVMs at 1057 days. The mRS score $>2$ upper $95 \%$ confidence interval was crossed by the lower outcome Spetzler-Ponce Class B at 3065 days. Such crossing did not occur for Spetzler-Ponce Class C ubAVMs.

\section{Discussion}

Our results showed that Spetzler-Ponce Class A ubAVMs treated by surgery had a better outcome than conservatively managed ubAVMs within a short period of time with a high rate of cure. Where the outcome is considered $\mathrm{mRS}$ score $>2$, both surgically treated Spetzler-Ponce Class A and Spetzler-Ponce Class B ubAVMs had a better outcome than conservatively managed ubAVMs within a short period of time. Therefore, in this cohort study, it is reasonable to conclude that surgery can be superior to conservative management for a defined group of patients.

These findings are in stark contrast to the results of ARUBA, where treatment was reported to be significantly worse than conservative management for ubAVMs. ${ }^{17}$ Although considered a high standard of evidence, for a multicentered RCT to be generalizable (that is, have ex- ternal validity), the application of ethical equipoise must result in a sum of subjects reflective of the real world. The large number of centers agreeing to participate but failing to enroll patients either reflects these centers' inability to recruit patients (despite the selection of these centers for this capability) or an inability to apply ethical equipoise. A major difference in how ubAVMs were managed between our study and ARUBA was that our interventions analyzed were $100 \%$ surgery, with surgery alone as the sole interventional treatment in $84 \%$ of patients $(285$ of 341 patients; 56 patients underwent preoperative embolization); compared with ARUBA where surgery was performed in $16 \%$ (18 of 114) of interventions and surgery alone was the sole interventional treatment in $4 \%$ (5 of 114) of interventional cases. As such, ARUBA cannot be considered a study assessing the role of surgery for ubAVMs ${ }^{17}$ Furthermore, the claim from ARUBA that the "baseline characteristics of trial participants are much the same as those representative of population-based cohorts" is true for sex, age, and presentation (factors that are unlikely to impact upon treatment bias) but is not necessarily true for those characteristics that influence the risk of surgery. Comparing characteristics of ARUBAenrolled patients with our patients reveals the following: Deep venous drainage was absent in $66 \%$ of ARUBA patients (95\% CI, 59-72\%), whereas it was absent in $89 \%$ of our patients (95\% CI 85\%-92\%); Spetzler-Ponce Class $\mathrm{C}$ classification was present in $10 \%$ of ARUBA patients (95\% CI $7 \%-15 \%)$, whereas it was present in $22 \%$ of our patients (95\% CI $18 \%-27 \%)$; and AVM $<3 \mathrm{~cm}$ was present in $62 \%$ of ARUBA patients (95\% CI 55\%-68\%), whereas it was present in $33 \%$ of our patients $(95 \%$ CI 29\%-38\%). Although referral bias for complex ubAVMs may have occurred in our case series, the differences may also be explained by distortion of patients considered to 


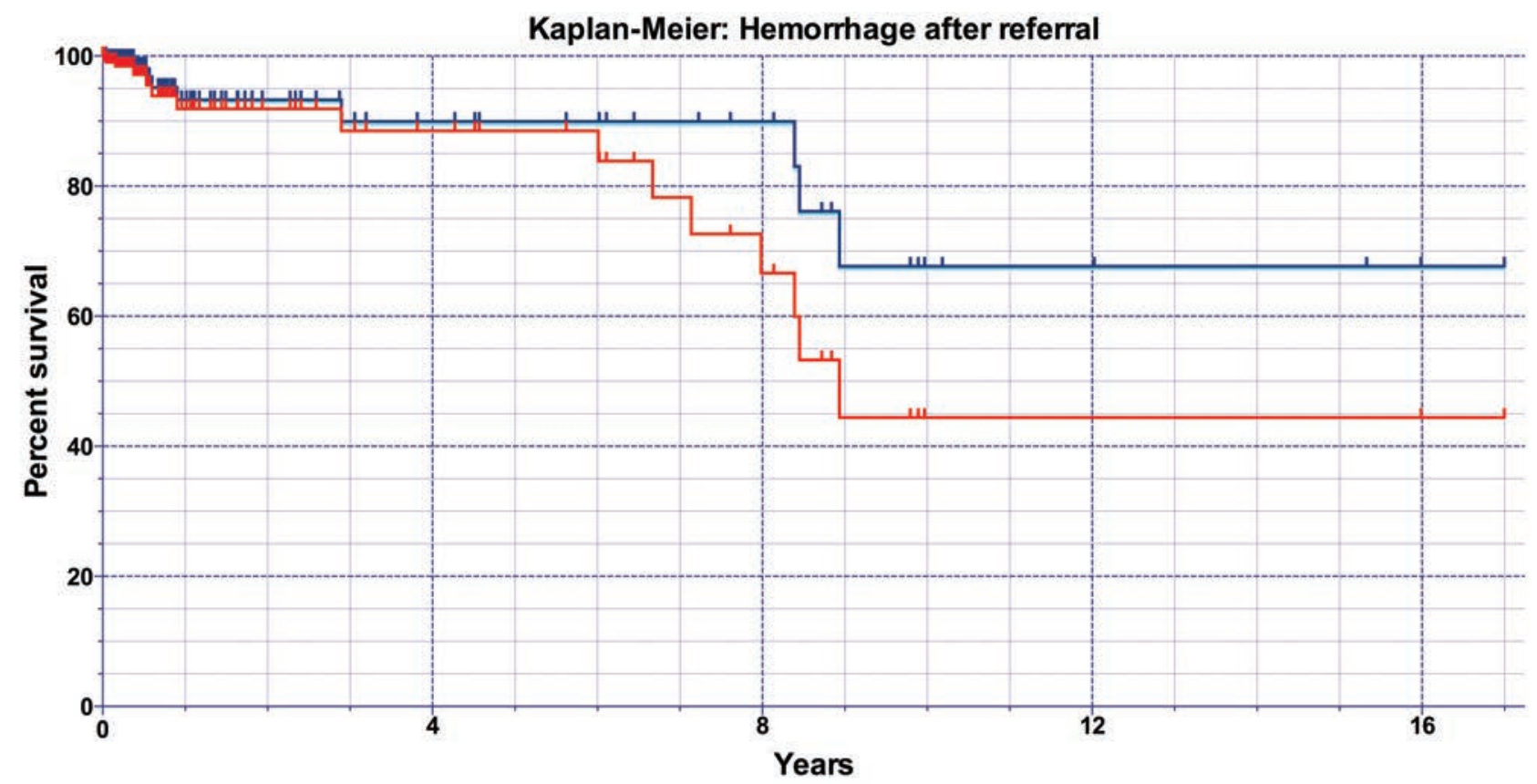

+ Hemorrhage

- Hemorrhage and clinical deterioration leading to $m R S>2$

- Hemorrhage and clinical deterioration leading to $m R S>1$

\begin{tabular}{|c|c|c|c|c|c|c|c|c|c|c|c|c|c|c|c|c|c|c|c|}
\hline \multicolumn{2}{|c|}{ Years } & Initial & 1 & 2 & 3 & 4 & 5 & 6 & 7 & 8 & 9 & 10 & 11 & 12 & 13 & 14 & 15 & 16 & 17 \\
\hline \multirow{3}{*}{ 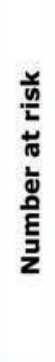 } & $I$ & 377 & 46 & 31 & 26 & 23 & 20 & 19 & 14 & 11 & 5 & 2 & 2 & 2 & 2 & 2 & 2 & 2 & 1 \\
\hline & 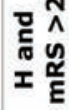 & 377 & 48 & 33 & 26 & 23 & 20 & 19 & 16 & 14 & 8 & 5 & 4 & 4 & 3 & 3 & 3 & 2 & 1 \\
\hline & 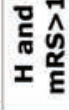 & 377 & 47 & 32 & 26 & 23 & 20 & 19 & 16 & 14 & 8 & 5 & 4 & 4 & 3 & 3 & 3 & 2 & 1 \\
\hline
\end{tabular}

FIG. 2. Kaplan-Meier curves and numbers at risk for the 377 patients with bAVMs enrolled in the risk of hemorrhage study. $\mathrm{H}=$ hemorrhage.

meet clinical equipoise enrolled in ARUBA. Given that selection bias may have occurred in ARUBA, the generalizability of conclusions needs to be questioned. This justifies the continued examination of case series at this time.

\section{Natural History}

Because of the lower risk of hemorrhage from ubAVMs compared with those presenting with hemorrhage, concern has been raised as to whether treatment of ubAVMs is justified. ${ }^{17}$ A meta-analysis found an annual ubAVM hemorrhage rate of $2.2 \%$ (95\% CI $1.7 \%-2.7 \%$ ). ${ }^{9}$ Of interest for ubAVMs, the rate of hemorrhage has been found to be considerably higher during the 1st year after diagnosis. ${ }^{11,12,33}$ In a prospective study from Japan, the rate of first hemorrhage was greater during the first 12 months after presentation $(4.8 \%) .{ }^{12}$ As there may be a nonlinear relationship between time from presentation and hemorrhage, the time from diagnosis to enrollment in prospective studies is important. As there was often a delay between referral and treatment, we used all our potential 377 patients with a ubAVM in the analysis of the risk of hemorrhage. Although our method using KaplanMeier product-limit method found an $8.1 \%$ 1st year risk of hemorrhage, when utilizing the method of these studies (calculated as the number of patients with hemorrhage during follow-up divided by case-years of follow-up) the risk of hemorrhage in our series is 5.7\%. This is marginally greater than previously published series for the 1 st year risk of hemorrhage. The 11.5\% 5-year risk of first hemorrhage is similar to that reported in the literature (Table $3)$. The cumulative hemorrhage rate found in ARUBA at 5 years was estimated to be approximately $12 \%$ from the Kaplan-Meier figure provided. Considering the number at risk in our study at each stage of follow-up, we believe our 

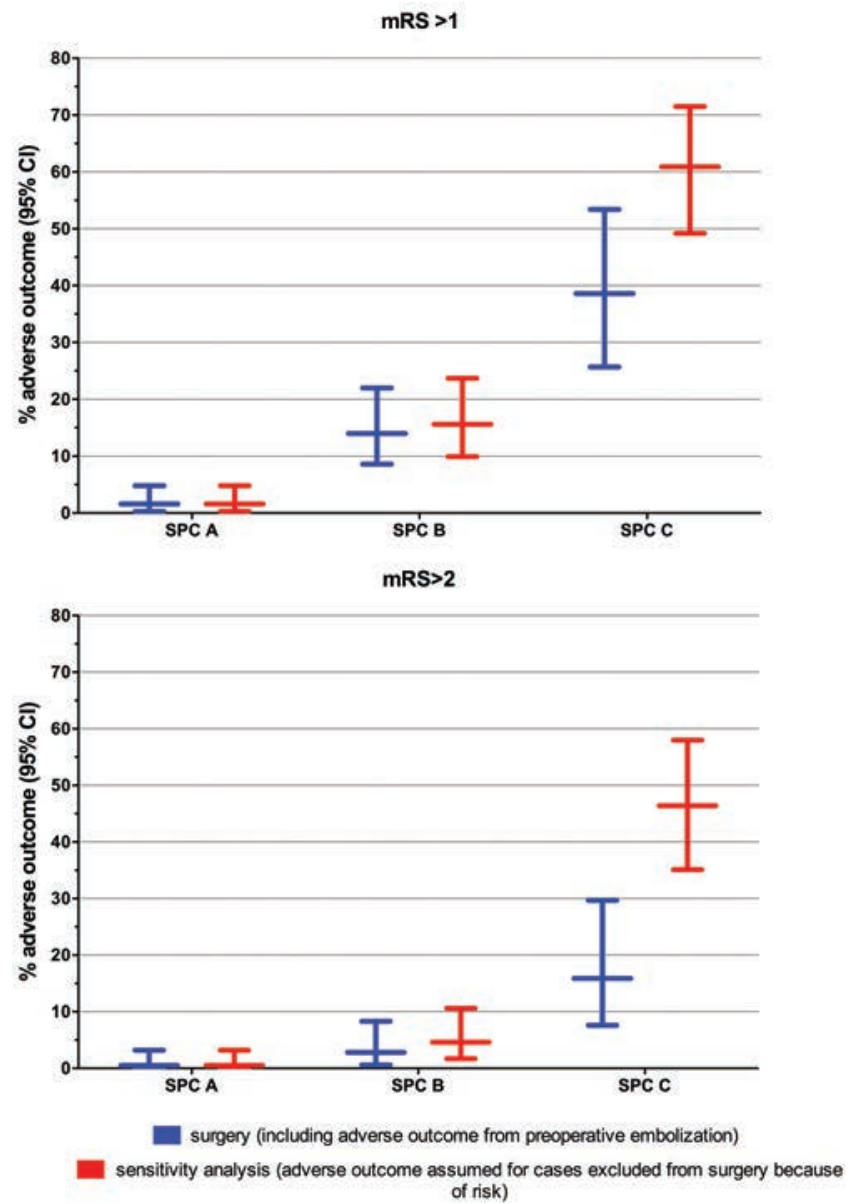

Fıg. 3. Sensitivity analysis and comparison between the adverse outcomes from surgery for 341 ubAVMs and that projected if 27 cases excluded from surgery underwent surgery and experienced an adverse outcome.

results are reliable for the first 5 years from initial referral. However, Hernesniemi and colleagues, who provide the longest long-term analysis (with a mean of 13.5 years) of 99 ubAVMs, found a cumulative first hemorrhage risk of $10 \%$ and $29 \%$ at 5 and 20 years, respectively. ${ }^{11}$ They excluded patients with less than 1 month of follow-up (which differs from our own analysis). On an annualized basis, our results suggest a risk of first hemorrhage of $2.3 \%$ per year over 5 years. This is within the range of literature estimates (Table 3 ) and is similar to $2.2 \%$ calculated by Gross and Du in their meta-analysis. ${ }^{9}$

Our finding that ubAVMs had a slightly greater risk of rupture in the first 12 months after diagnosis (Table 3) than previously reported may be explained by the inclusion of patients from the time of referral, capturing patients who otherwise would have been excluded if the commencement of the database had coincided with admission to hospital. That a higher rate of hemorrhage occurs early in some series may be explained by a small number of patients presenting with clinical symptoms due to changes within the ubAVM that alter the hemodynamics (for example, venous outflow stenosis or occlusion) that might predispose to hemorrhage. ${ }^{6,15,16,32}$ Such changing hemodynamics would not be captured in most database interrogations. The importance of knowing the time from diagnosis in estimating the future risk needs to be considered.

The clinical consequence of hemorrhage for ubAVMs in our experience was significant, resulting in a permanent adverse outcome with $\mathrm{mRS}$ score $>2$ in more than two-thirds (of these, nearly half resulted in death). This is in the range of outcomes reported in the literature. Of 77 patients who suffered hemorrhage, Crawford et al. reported a $25 \%$ mortality and $19 \%$ incidence of hemiparesis. ${ }^{3}$ Brown and colleagues reported a similar 29\% mortality and $16 \%$ morbidity from hemorrhage in follow-up. ${ }^{2}$ Ondra and colleagues reported that $85 \%$ of 64 patients died or sustained major permanent morbidity. ${ }^{20} \mathrm{Da}$ Costa and colleagues reported 89 hemorrhages after enrollment to their bAVM database (both unruptured and ruptured bAVMs) for a $6 \%$ mortality and 35\% significant permanent disability. ${ }^{4}$ It is reasonable to assume that approximately half of those experiencing hemorrhage from a ubAVM will have a significant permanent deficit or fatal outcome.

Arranging a classification for ubAVMs according to characteristics that impact upon risk of hemorrhage is an appealing strategy. Stapf and colleagues identified a combination of a number of factors that may predict a high rate of hemorrhage, and the corollary was also proposed that in the absence of these factors the risk of hemorrhage is very low. ${ }^{28}$ Our results suggest that such classification would have limited utility in predicting the risk of ubAVM hemorrhage during the first years after diagnosis for our cohort. In our cases, deep location had a weak predictive value and no other variable was significant.

\section{Surgical Outcomes}

We have previously reported the lower risk for surgery for Spetzler-Ponce Class A bAVMs compared with Spetzler-Ponce Class B and Spetzler-Ponce Class C bAVMs. Also, we previously reported that very few Spetzler-Ponce Class A bAVMs were not recommended for surgery due to perceived risks, ${ }^{5}$ which differed from the higher grades where a number of cases were selected for conservative management because of the perceived risk from surgery. Therefore, to assess the generalizable risk from surgery for all Spetzler-Ponce Class B and Spetzler-Ponce Class C bAVMs, consideration needs to be made of those eligible patients who do not undergo surgery because of perceived risk from surgery. The 5 patients with Spetzler-Ponce Class A bAVMs recommended for conservative management were either elderly or had comorbidity suggesting an unlikelihood of benefit from surgery and were considered not eligible for surgery. Our findings that Spetzler-Ponce Class A ubAVMs treated by surgery had a new permanent neurological deficit (mRS score $>1$ outcome) of $1.6 \%$ due to surgery can be generalized to all eligible cases (treated by surgery or not). With regard to Spetzler-Ponce Class B ubAVMs, 2 of 109 eligible patients $(<65$ years and without significant comorbidity) were excluded due to a perceived higher risk from surgery. Had both of these cases been incorporated in the surgical outcomes and had an adverse outcome, $15.6 \%$ of these cases would have had an adverse outcome and in 


\section{Surgery for unruptured arteriovenous malformations}

TABLE 4: Characteristics of cases included in the surgical and in the sensitivity analysis groups

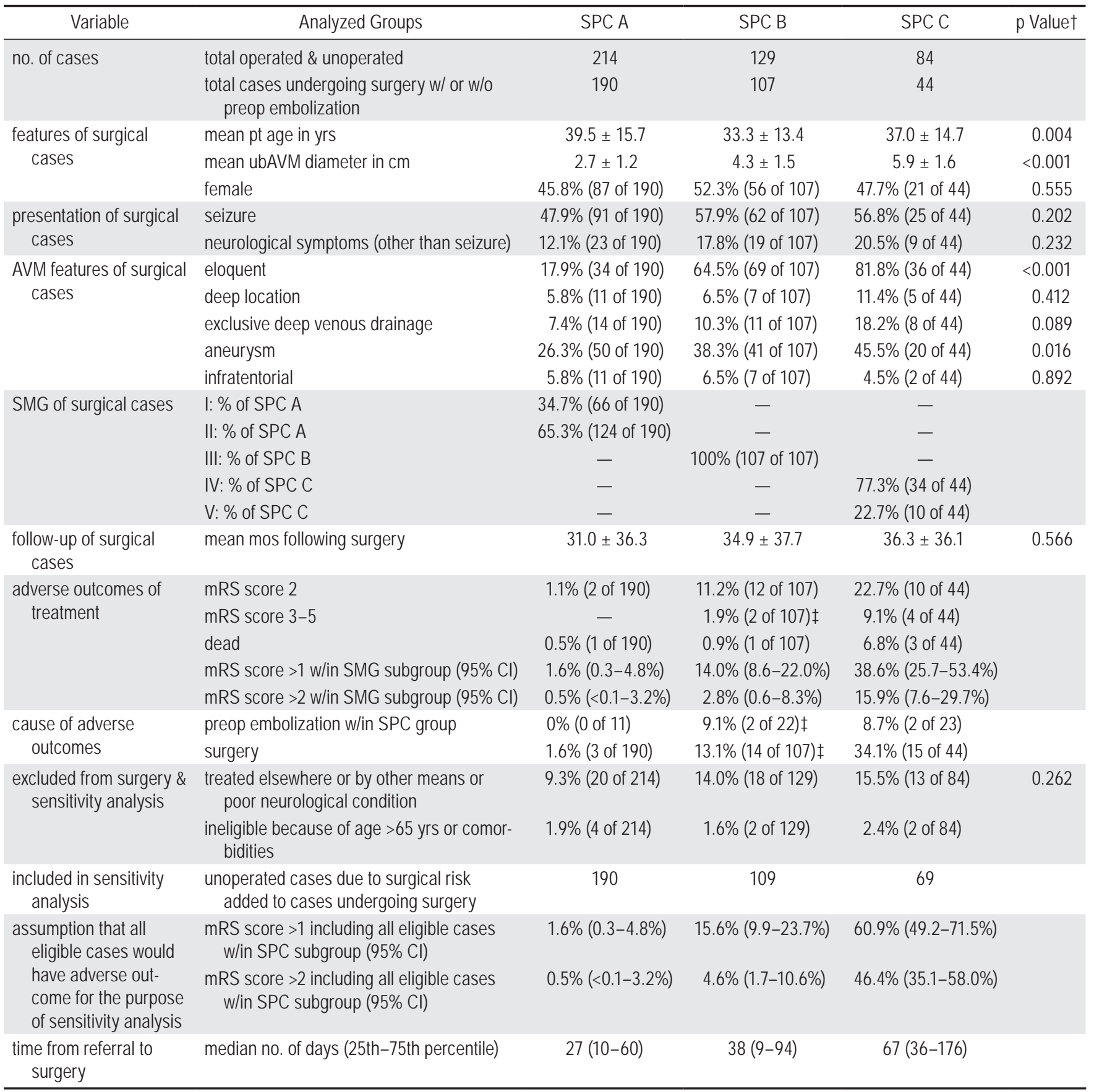

* Values in parentheses are number of cases (\%) unless noted otherwise. Mean values are presented as the mean \pm SD. pt = patient; SMG = SpetzlerMartin grade; SPC = Spetzler-Ponce class.

$\dagger$ Chi-square test for categorical variable and 1-way ANOVA test for continuous variables.

$\ddagger$ One patient experienced 2 adverse events, related to both preoperative embolization and surgery.

$4.6 \%$ of cases would this have led to an mRS score $>2$. The results for Spetzler-Ponce Class C ubAVMs cannot be generalized due to the large number of potentially eligible patients ( $<65$ years and without significant comorbidity) excluded because of perceived higher risk from surgery. Had these patients been incorporated in the surgical out- comes and had an adverse outcome, the adverse outcome rate would be closer to $61 \%$, which is greater than the $39 \%$ seen for those cases that were selected for surgery.

Despite the demonstration that the Spetzler-Martin grading system ${ }^{25}$ is a good way of stratifying the risks from surgery, this has not been reported for ubAVMs be- 

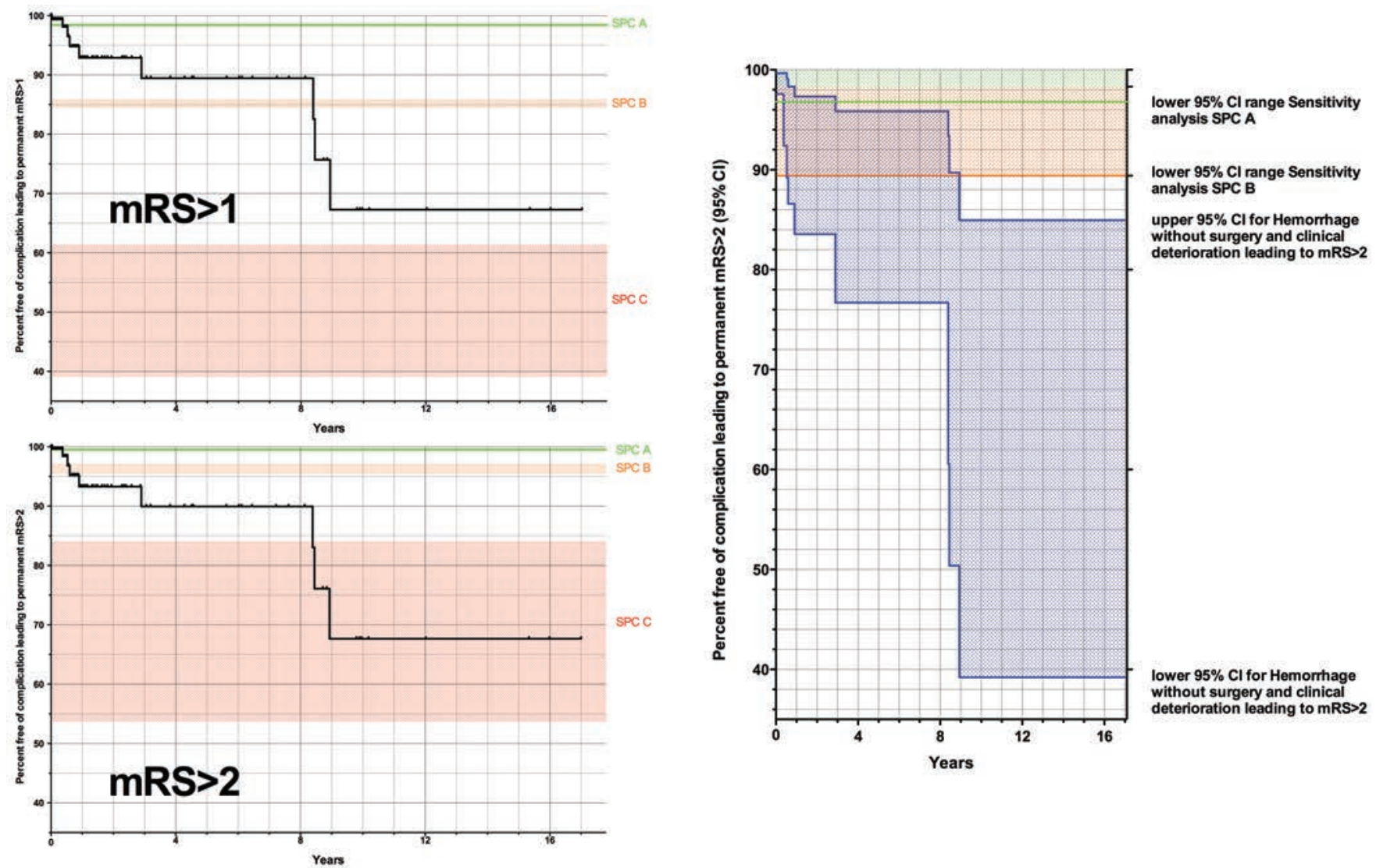

The surgical risk includes the actual risk of surgical cases (upper border of color band) and the risk of the sensitivity analysis incorporating cases eligible but not operated because of perceived risk (lower border of color band).

\section{5\% $\mathrm{CI} \mathrm{KM} \%$ risk of hemorrhage from ubAVM with $\mathrm{mRS}>2$ $95 \% \mathrm{Cl}$ surgery SPC A and SPC B not causing $\mathrm{mRS}>2$}

FIG. 4. Modified Rankin Scale score outcomes for surgery, sensitivity analysis of surgery, and hemorrhage from ubAVM. The mRS outcome of Kaplan-Meier percentage of natural history (377 patients) is superimposed on sensitivity analysis of surgery. A total of 190 patients had Spetzler-Ponce Class A ubAVMs, 109 had Spetzler-Ponce Class B ubAVMs, and 69 had Spetzler-Ponce Class C ubAVMs. KM = Kaplan-Meier.

fore. Our finding that the Spetzler-Martin grading system applied to ubAVM surgery was useful in stratifying the incidence of adverse outcomes.

A proportion of the morbidity and mortality arose as a consequence of preoperative embolization. We have previously published our results of embolization and the lack of evidence of benefit from preoperative embolization for cases of Spetzler-Ponce Class A ubAVMs. ${ }^{18,19}$ Consideration should be given to early surgery, elimination of the use of embolization, and perhaps reduction in the use of preoperative diagnostic DSA for Spetzler-Ponce Class A ubAVMs to reduce adverse outcomes from all causes in this group.

For Spetzler-Ponce Class B and Spetzler-Ponce Class $\mathrm{C}$ ubAVMs, the risk of an adverse outcome from surgery is high. Therefore, recommending management for these patients remains a highly nuanced process and may not be made for several years after first referral. Despite the high morbidity for this group, the $1 \%$ and $7 \%$ mortality for Spetzler-Ponce Class B and Spetzler-Ponce Class C ubAVMs, respectively, are likely lower than the long-term mortality if untreated. This mortality may come into consideration in the decision making for some patients (particularly younger patients).

\section{Comparing Surgery and Conservative Management}

We believe that we can generalize the conclusion that our results confirm that Spetzler-Ponce Class A ubAVMs treated by surgery have a better outcome than conservatively managed ubAVMs. This was investigated by looking at the most optimistic boundary of our results of natural history (the upper 95\% confidence interval for not experiencing an adverse outcome) with the most pessimistic boundary of surgery (the lower 95\% confidence interval for not experiencing an adverse outcome). Superimposing these $95 \%$ boundaries, for $\mathrm{mRS}$ score $>$ 
1 there was crossover within 9 years and for $\mathrm{mRS}>2$ crossover was within 3 years of surgery. Therefore, our results suggest a 90\% likelihood (combining the two 95\% confidence intervals) that there is a benefit for surgery over conservative treatment within 3 years of treatment for our cases. The superimposition of sensitivity analysis upon the natural history curve suggests a tendency to an advantage for Spetzler-Ponce Class B ubAVMs; however, using the higher level of confidence by superimposing the 95\% boundaries, the outcome for surgery for SpetzlerPonce Class B and Spetzler-Ponce Class C ubAVMs may not be better than conservative management of ubAVMs. However, there are a number of complex factors that may come into play for individual patients (such as the likely lower mortality rate from surgery) that result in the recommendation for surgery despite the daunting morbidity. Although we have shown that for selected cases surgery can be better than medical management, a weakness of our results relates to the generalizability to other surgeons and institutions. An avenue for future research is to explore results from larger administrative areas to see whether results for the population of patients being treated by surgery are better than medical management.

\section{Conclusions}

Our study suggests that surgical outcomes for Spetzler-Ponce Class A ubAVMs can be better than those for conservative management. The difficulty in performing RCTs is clear from ARUBA. The prospect of mounting a future RCT becomes increasingly difficult as the window of ethical equipoise continues to close because there is increasing evidence for a specific management pathway (even if this evidence is from cohort series). Future research in this area should concentrate on the selection process for management pathways that provide enough context to inform consensus and identify those that can best be managed by surgery.

\section{Disclosure}

The authors report no conflict of interest concerning the materials or methods used in this study or the findings specified in this paper. Dr. Bervini was supported by a scholarship funded by Johnson and Johnson Medical, Pty Limited.

Author contributions to the study and manuscript preparation include the following. Conception and design: Morgan. Acquisition of data: Morgan, Bervini. Analysis and interpretation of data: Morgan, Bervini, Heller. Drafting the article: Morgan, Bervini, Ritson. Critically revising the article: all authors. Reviewed submitted version of manuscript: all authors. Approved the final version of the manuscript on behalf of all authors: Morgan. Statistical analysis: Morgan, Bervini, Heller. Administrative/technical/material support: Morgan. Study supervision: Morgan.

\section{References}

1. Bambakidis NC, Cockroft K, Connolly ES, Amin-Hanjani S, Morcos J, Meyers PM, et al: Preliminary results of the ARUBA study. Neurosurgery 73:E379-E381, 2013

2. Brown RD Jr, Wiebers DO, Forbes G, O'Fallon WM, Piepgras DG, Marsh WR, et al: The natural history of unruptured intracranial arteriovenous malformations. J Neurosurg 68:352357,1988
3. Crawford PM, West CR, Chadwick DW, Shaw MD: Arteriovenous malformations of the brain: natural history in unoperated patients. J Neurol Neurosurg Psychiatry 49:1-10, 1986

4. da Costa L, Wallace MC, Ter Brugge KG, O'Kelly C, Willinsky RA, Tymianski M: The natural history and predictive features of hemorrhage from brain arteriovenous malformations. Stroke 40:100-105, 2009

5. Davidson AS, Morgan MK: How safe is arteriovenous malformation surgery? A prospective, observational study of surgery as first-line treatment for brain arteriovenous malformations. Neurosurgery 66:498-505, 2010

6. Dobbelaere P, Jomin M, Clarrisse J, Laine E: [Prognostic importance of the study of venous drainage in cerebral arteriovenous aneurysms.] Neurochirurgie 25:178-184, 1979 (Fr)

7. Fullerton HJ, Achrol AS, Johnston SC, McCulloch CE, Higashida RT, Lawton MT, et al: Long-term hemorrhage risk in children versus adults with brain arteriovenous malformations. Stroke 36:2099-2104, 2005

8. Graf CJ, Perret GE, Torner JC: Bleeding from cerebral arteriovenous malformations as part of their natural history. $\mathbf{J}$ Neurosurg 58:331-337, 1983

9. Gross BA, Du R: Natural history of cerebral arteriovenous malformations: a meta-analysis. Clinical article. J Neurosurg 118:437-443, 2013

10. Halim AX, Johnston SC, Singh V, McCulloch CE, Bennett JP, Achrol AS, et al: Longitudinal risk of intracranial hemorrhage in patients with arteriovenous malformation of the brain within a defined population. Stroke 35:1697-1702, 2004

11. Hernesniemi JA, Dashti R, Juvela $S$, Väärt $K$, Niemelä $M$, Laakso A: Natural history of brain arteriovenous malformations: a long-term follow-up study of risk of hemorrhage in 238 patients. Neurosurgery 63:823-831, 2008

12. Itoyama $Y$, Uemura S, Ushio Y, Kuratsu J, Nonaka N, Wada H, et al: Natural course of unoperated intracranial arteriovenous malformations: study of 50 cases. J Neurosurg 71:805-809, 1989

13. Kim H, Sidney S, McCulloch CE, Poon KY, Singh V, Johnston SC, et al: Racial/ethnic differences in longitudinal risk of intracranial hemorrhage in brain arteriovenous malformation patients. Stroke 38:2430-2437, 2007

14. Lawton MT, Kim H, McCulloch CE, Mikhak B, Young WL: A supplementary grading scale for selecting patients with brain arteriovenous malformations for surgery. Neurosurgery 66:702-713, 2010

15. Marks MP, Lane B, Steinberg GK, Chang PJ: Hemorrhage in intracerebral arteriovenous malformations: angiographic determinants. Radiology 176:807-813, 1990

16. Miyasaka Y, Yada K, Ohwada T, Kitahara T, Kurata A, Irikura $\mathrm{K}$ : An analysis of the venous drainage system as a factor in hemorrhage from arteriovenous malformations. J Neurosurg 76:239-243, 1992

17. Mohr JP, Parides MK, Stapf C, Moquete E, Moy CS, Overbey JR, et al: Medical management with or without interventional therapy for unruptured brain arteriovenous malformations (ARUBA): a multicentre, non-blinded, randomised trial. Lancet 383:614-621, 2014

18. Morgan MK, Davidson AS, Koustais S, Simons M, Ritson EA: The failure of preoperative ethylene-vinyl alcohol copolymer embolization to improve outcomes in arteriovenous malformation management: case series. Clinical article. J Neurosurg 118:969-977, 2013

19. Morgan MK, Zurin AA, Harrington T, Little N: Changing role for preoperative embolisation in the management of arteriovenous malformations of the brain. J Clin Neurosci 7:527-530, 2000

20. Ondra SL, Troupp H, George ED, Schwab K: The natural history of symptomatic arteriovenous malformations of the brain: a 24-year follow-up assessment. J Neurosurg 73:387391,1990 


\section{Bervini et al.}

21. Pollock BE, Flickinger JC, Lunsford LD, Bissonette DJ, Kondziolka D: Hemorrhage risk after stereotactic radiosurgery of cerebral arteriovenous malformations. Neurosurgery 38:652-661, 1996

22. Redekop G, TerBrugge K, Montanera W, Willinsky R: Arterial aneurysms associated with cerebral arteriovenous malformations: classification, incidence, and risk of hemorrhage. J Neurosurg 89:539-546, 1998

23. Schaller C, Schramm J, Haun D: Significance of factors contributing to surgical complications and to late outcome after elective surgery of cerebral arteriovenous malformations. J Neurol Neurosurg Psychiatry 65:547-554, 1998

24. Spears J, Terbrugge KG, Moosavian M, Montanera W, Willinsky RA, Wallace MC, et al: A discriminative prediction model of neurological outcome for patients undergoing surgery of brain arteriovenous malformations. Stroke 37:14571464,2006

25. Spetzler RF, Martin NA: A proposed grading system for arteriovenous malformations. J Neurosurg 65:476-483, 1986

26. Spetzler RF, Ponce FA: A 3-tier classification of cerebral arteriovenous malformations. Clinical article. J Neurosurg 114: 842-849, 2011

27. Stapf C, Khaw AV, Sciacca RR, Hofmeister C, Schumacher HC, Pile-Spellman J, et al: Effect of age on clinical and morphological characteristics in patients with brain arteriovenous malformation. Stroke 34:2664-2669, 2003

28. Stapf C, Mast H, Sciacca RR, Choi JH, Khaw AV, Connolly ES, et al: Predictors of hemorrhage in patients with untreated brain arteriovenous malformation. Neurology 66:1350-1355, 2006
29. Stapf C, Mohr JP, Pile-Spellman J, Sciacca RR, Hartmann A, Schumacher HC, et al: Concurrent arterial aneurysms in brain arteriovenous malformations with haemorrhagic presentation. J Neurol Neurosurg Psychiatry 73:294-298, 2002

30. Stapf C, Mohr JP, Sciacca RR, Hartmann A, Aagaard BD, Pile-Spellman J, et al: Incident hemorrhage risk of brain arteriovenous malformations located in the arterial borderzones. Stroke 31:2365-2368, 2000

31. Svien HJ, McRae JA: Arteriovenous anomalies of the brain. Fate of patients not having definitive surgery. J Neurosurg 23:23-28, 1965

32. Viñuela F, Nombela L, Roach MR, Fox AJ, Pelz DM: Stenotic and occlusive disease of the venous drainage system of deep brain AVM's. J Neurosurg 63:180-184, 1985

33. Yamada S, Takagi Y, Nozaki K, Kikuta K, Hashimoto N: Risk factors for subsequent hemorrhage in patients with cerebral arteriovenous malformations. J Neurosurg 107:965-972, 2007

Manuscript submitted December 5, 2013.

Accepted July 10, 2014.

Please include this information when citing this paper: published online August 8, 2014; DOI: 10.3171/2014.7.JNS132691.

Address correspondence to: Michael Kerin Morgan, M.D., Health and Medical Development, Macquarie University, 2 Technology Pl., Macquarie University, Sydney, NSW 2109, Australia. email: michael.morgan@mq.edu.au. 


\section{Editorial}

\section{Surgical management of unruptured cerebral arteriovenous malformations}

\author{
Mohamed Samy Elhammady, M.D., \\ and Roberto C. Heros, M.D.
}

Department of Neurosurgery, University of Miami, Florida

This issue of the Journal of Neurosurgery includes an excellent paper by Bervini et al. from Professor Morgan's service at Macquarie University in Sydney, Australia. ${ }^{2}$ This well-respected group has one of the largest experiences in the world with cerebral arteriovenous malformations (AVMs). In this study, the authors sought to ascertain the natural history of unruptured brain AVMs with regard to risk of rupture as well as the morbidity and mortality associated with resection. The authors retrospectively identified all patients with unruptured brain AVMs who were referred to their institution from a prospectively maintained AVM database consisting of both treated and untreated lesions. Over a 24-year period, a total of 427 patients with unruptured cerebral AVMs were identified. All patients with more than 1 day of follow-up $(n=377)$ were analyzed for risk of hemorrhage, irrespective of the management plan, from the date of initial consultation or referral to the date of last available follow-up or until the initiation of treatment. Radiologically confirmed hemorrhage unrelated to treatment occurred in 16 patients during a total of 279 case-years of follow-up. Permanent disability following hemorrhage resulted in a modified Rankin Scale (mRS) score $>1$ in $88 \%$ (14 cases), mRS score $>2$ in $69 \%$, and death in $31 \%$ of the patients. The cumulative rate of hemorrhage using Kaplan-Meier analysis at 1 and 5 years was $8.1 \%$ and $11.5 \%$, respectively. The annualized risk of hemorrhage over the first 5 years was $2.3 \%$. The only variable associated with a significantly shorter time to hemorrhage was deep location by univariate analysis.

The risk from resection was assessed in 2 ways. First, the authors analyzed the surgical outcomes in patients who actually underwent resection based on AVM grade. The authors classified AVMs according to Spetzler-Ponce Class where Class A comprised Spetzler-Martin Grade I and II lesions, Class B comprised Spetzler-Martin Grade III lesions, and Class C comprised Spetzler-Martin Grade IV and V lesions. Complications were defined as any permanent neurological deficits following surgery, including those related to preoperative embolization, that resulted in an mRS score $>1$ at last follow-up. The authors then performed an interesting sensitivity analysis to estimate the true risk of surgery for all AVM grades and not only those selected based on a perceived favorable risk-benefit ratio. The authors included patients who were eligible for surgery but did not undergo resection because of perceived excess surgical morbidity with those who actually underwent resection. Patients were considered eligible for surgery if they were younger than 65 years and did not have significant comorbidities. These added unoperated cases were assumed to have an adverse outcome for the purpose of the sensitivity analysis.

For patients with Spetzler-Ponce Class A lesions treated by surgery $(n=190)$, the risk of a new permanent deficit resulting in an mRS score $>1$ or $\mathrm{mRS}$ score $>2$ was $1.6 \%$ and $0.5 \%$, respectively. None of the eligible patients with Spetzler-Ponce Class A lesions were excluded because of perceived excessive surgical risk and thus a sensitivity analysis was not performed. For patients with Spetzler-Ponce Class B lesions treated by surgery (n $=107$ ), the risk of a new permanent deficit resulting in an mRS score $>1$ was $14 \%$ and mRS score $>2$ was $2.8 \%$. Two eligible patients with Spetzler-Ponce Class B lesions were excluded because of perceived excessive surgical risk. The sensitivity analysis showed that if these cases had been included the risk of a new permanent neurological deficit resulting in an $\mathrm{mRS}$ score $>1$ or $\mathrm{mRS}$ score $>2$ would have been as high as $15.6 \%$ and $4.6 \%$, respectively. For patients with Spetzler-Ponce Class $\mathrm{C}$ lesions treated by surgery $(n=44)$, the risk of a new permanent deficit resulting in an mRS score $>1$ was $38.6 \%$ and an mRS score $>2$ was $15.9 \%$. Twenty-five eligible patients were denied surgery due to perceived excessive surgical morbidity. The sensitivity analysis showed that if these cases had been included the risk of a new permanent neurological deficit resulting in an mRS score $>1$ or $\mathrm{mRS}$ score $>2$ would have been as high as $60.9 \%$ and $46.4 \%$, respectively.

The authors then superimposed the risk of surgery resulting in an mRS score $>1$ upon the Kaplan-Meier curve of the risk of hemorrhage and found that the crossover occurred before 5 months for Spetzler-Ponce Class A lesions and between 8 and 9 years for Spetzler-Ponce Class B lesions but did not occur for Spetzler-Ponce Class C lesions. When surgical outcomes resulting in an mRS score $>2$ were superimposed, the crossover occurred before 5 months, between 6 and 8 months, and beyond 8 years for Spetzler-Ponce Class A, B, and C lesions, respectively. The authors concluded that surgery for Spetzler-Ponce 
Class A unruptured cerebral AVMs beats the natural history. They further confirmed this conclusion by superimposing the most optimistic boundary of the natural history (the upper 95\% confidence interval for not experiencing an adverse outcome) with the most pessimistic boundary of the surgical sensitivity analysis (the lower 95\% confidence interval for not experiencing an adverse outcome) and found that the crossover occurred within 9 years for mRS score $>2$ and within 3 years for $m R S>$ score 1 , suggesting a $90 \%$ chance of surgical benefit over conservative treatment within 3 years for unruptured SpetzlerPonce Class A AVMs. On the other hand, a similar analysis for Spetzler-Ponce Class B and Spetzler-Ponce Class $\mathrm{C}$ lesions suggested that surgery might not be better than conservative management.

The article, which is very well written and discussed, has some limitations, which were acknowledged by the authors. This was a nonrandomized retrospective analysis of a prospective cohort of patients. The natural history data presented by the authors must be interpreted with some skepticism. They studied patients from the time of diagnosis to the time of treatment, hemorrhage, or the date of the last follow-up in those patients who did not have hemorrhage or treatment. In this group of patients, the average time between initial referral and treatment, hemorrhage, or last follow-up was 270 days with a range of 1 to 5840 days. Why such a delay in treatment in these patients? One could conceive that there was a bias in delaying treatment in those patients who for one reason or another were suspected to have a lesser risk of hemorrhage. Nevertheless, the risk of hemorrhage of approximately $2.3 \%$ per year during the first 5 years of follow-up calculated in this fashion by these authors is very similar to that found in other studies that address specifically the natural history of unruptured AVMs, as discussed and referenced by the authors.

More straightforward are the data provided by the authors in their surgical results. Clearly, it could be argued that the results of a highly skilled and extremely experienced neurovascular surgeon such as Professor Morgan cannot be generalized. However, his results are comparable to those reported in several series, including our own. ${ }^{1,4,6-8}$ Still, it is very likely that these excellent results can only be achieved in centers with considerable experience in the treatment of AVMs, and, in this respect, the results reported in this study may not be generalizable; however, should not most patients with such relatively uncommon and complicated lesions as cerebral AVMs be referred for elective treatment to experienced centers?

Undoubtedly, the design of this retrospective study was intended as a direct challenge to the recently reported A Randomized Trial of Unruptured Brain Arteriovenous Malformations (ARUBA) results. We have commented in some detail in a recent editorial on the need to exert caution in the interpretation of the results of the ARUBA study and we will not repeat that discussion here. ${ }^{3}$ The fact is that, despite the widely discussed limitations of the results of the ARUBA studies, many have interpreted such results as indicative of the fact that no unruptured cerebral AVM should be treated at all. Hence, the importance of the study by Professor Morgan and his colleagues that, when supplemented by similar results reported in other large series, provide robust support for recommending treatment, specifically excision, to all relatively young and healthy patients with an unruptured Spetzler-Martin Grade I or II AVM. The results of treatment, which is frequently multimodality, with Spetzler-Martin Grade IV and V AVMs, even in the best hands, as evidenced in this particular study, strongly argue against recommending treatment to patients with unruptured high-grade AVMs. As many have discussed, including ourselves in a recent editorial, $, 3,5$ decision making with Spetzler-Martin Grade III malformations is indeed difficult since this is a very heterogeneous group of lesions. Suffice to say that with these AVMs, treatment decisions must be highly individualized and that in general, when dealing with unruptured Grade III AVMs, a relatively conservative attitude is desirable.

We thank Professor Morgan and his group for providing us with an excellent article that, we believe, will be highly influential.

(http://thejns.org/doi/abs/10.3171/2014.5.JNS14240)

\section{Disclosure}

The authors report no conflict of interest.

\section{References}

1. Baskaya MK, Jea A, Heros RC, Javahary R, Sultan A: Cerebral arteriovenous malformations. Clinical Neurosurgery 53:114-144, 2006

2. Bervini D, Morgan MK, Ritson EA, Heller G: Surgery for unruptured arteriovenous malformations of the brain is better than conservative management for selected cases: a prospective cohort study. Clinical article. J Neurosurg [epub ahead of print August 8, 2014. DOI: 10.3171/2014.7.JNS132691]

3. Elhammady MS, Heros RC: Editorial. Stereotactic radiosurgery for Spetzler-Martin Grade III arteriovenous malformations. J Neurosurg 120:970-972, 2014

4. Heros RC, Korosue K, Diebold PM: Surgical excision of cerebral arteriovenous malformations: late results. Neurosurgery 26:570-578, 1990

5. Lawton MT: Spetzler-Martin Grade III arteriovenous malformations: surgical results and a modification of the grading scale. Neurosurgery 52:740-749, 2003

6. Pikus HJ, Beach ML, Harbaugh RE: Microsurgical treatment of arteriovenous malformations: analysis and comparison with stereotactic radiosurgery. J Neurosurg 88:641-646, 1998

7. Sisti MD, Koder A, Stein BM: Microsurgery for 67 intracranial arteriovenous malformations less than $3 \mathrm{~cm}$ in diameter. J Neurosurg 79:653-660, 1993

8. Spetzler RF, Martin NA: A proposed grading system for arteriovenous malformations. J Neurosurg 65:476-483, 1986

\section{Response}

Michael K. Morgan, M.D., ANd David Bervini, M.Adv.Surg.

Macquarie University Hospital, Macquarie University, Sydney, New South Wales, Australia

We thank the authors for their thoughtful response to our article. Two issues raised by the authors that need to 


\section{Editorial}

be addressed include delay to treatment and the generalizability of the surgical results.

The delay between referral and treatment was incorporated in the calculation of the natural history data. This was important in our study as we needed to find the $95 \%$ confidence intervals of the risk of first hemorrhage for the purpose of our comparison between surgery and no treatment of unruptured brain AVMs (ubAVMs). No 95\% confidence interval existed in the literature. Therefore, we included the period between referral and surgery in the operated cases along with the unoperated cases to establish the $95 \%$ confidence interval of the risk of next rupture. Because at 5 and 6 years the mean fell into the $95 \%$ confidence interval range of means reported in the metaanalysis of Gross and $\mathrm{Du},{ }^{1}$ we believe our results for next hemorrhage reflect the experience of others. The delay to treatment average differs considerably from the medians. The median time between referral and treatment was 27 days (75th percentile 60 days), 38 days (75th percentile 94 days), and 67 days (75th percentile 176 days) for Spetzler-Ponce Class A, B, and C lesions, respectively. ${ }^{2}$ For ubAVMs this time delay is not unusual, as in our practice we encourage patients to take time to think about what we have recommended before coming to a final decision. This is especially so for the more complex brain AVMs (bAVMs). Of course, this influences the mix of cases in the risk to rupture group (represented by more high-grade bAVMs). Having said this, there is little compelling evidence that suggests that different grades of unruptured bAVMs have different risk of rupture.

The question of generalizability of results is also important. We accept that in cohort studies the results are probably not generalizable. However, as Drs. Elhammady and Heros point out, and as Spetzler and Ponce have re- viewed, there are a number of surgical series with very similar results to ours (although these series incorporate both ruptured and ubAVMs). ${ }^{2}$ We believe that the important question of generalizability is of lesser importance than answering the question asked by ARUBA or by our study. There is a fundamental difference in these questions. ARUBA has asked, "IS" treatment of ubAVMs (by methods commonly recommended in units with a bias towards treatment modalities that are non-surgical) superior to no treatment ("best medical management")? However, our question was, "CAN" surgical treatment of ubAVMs be superior to no treatment? This is not addressed by ARUBA in which $82 \%$ of patients in the treatment arm were treated by means other than surgery. We believe that surgical treatment of ubAVMs can be superior to no treatment and that this conclusion in our study is realistic.

The argument regarding the type of center that should manage bAVMs is important. Centralization in academic or specialized units may have an advantage to ensure that there are enough cases of bAVMs to facilitate expertise in surgical treatment, benchmarking of outcomes, and modification of practice (continuing learning).

\section{References}

1. Gross BA, Du R: Natural history of cerebral arteriovenous malformations: a meta-analysis. Clinical article. J Neurosurg 118:437-443, 2013

2. Spetzler RF, Ponce FA: A 3-tier classification of cerebral arteriovenous malformations. Clinical article. J Neurosurg 114:842-849, 2011

Please include this information when citing this paper: published online August 8, 2014; DOI: 10.3171/2014.5.JNS14240. 